https://doi.org/10.48009/1_iis_2005_251-257

\title{
USING WEB POLLS TO ENHANCE SOCIAL INTERACTION IN COMPUTER-MEDIATED DISTANCE EDUCATION
}

\author{
Joseph-Rene Corbeil, The University of Texas at Brownsville, rene.corbeil@utb.edu
}

\begin{abstract}
Polling students during asynchronous discussions is a simple technique to get students to actively participate in an online class. The instructor posts a question using polling software and students cast their votes. This paper will: (1) discuss the use of online polls to enhance social interaction in computer-mediated discussions; (2) identify some challenges to participation in computer-mediated discussions; (3) provide examples of poll use in online classes; and (4) discuss students' perceptions of online polls.
\end{abstract}

Keywords: Online polls, social interaction, computer-mediated communication, distance education

\section{INTRODUCTION}

Having survived another presidential election, many people have strong reservations regarding polls. Despite their recent notoriety, polls have found a purpose in education, and most notably, in computer-mediated distance learning. Instructors of online courses can use web-based polls to gauge student opinion regarding key issues or to determine class-wide comprehension of important concepts. Polls can also be used for consensus building or to structure, summarize, and enhance social interaction in computer-mediated asynchronous discussions.

Polling students during asynchronous discussions is a simple technique to get students to actively participate in an online class. The instructor posts a question through an online poll and asks students to "vote" on the question. Polling is an informal assessment that provides instant feedback to students and instructors alike. In large classes, it may provide the only opportunity for students to voice their opinions on a subject.

\section{The Nature of Social Interaction}

The current push in distance education research is to promote, encourage, and support social interaction in computer-mediated distance education courses. Interaction is an essential attribute of life. According to Wilkerson, it provides substance to the ecological, cultural, organizational, social, and psychological aspects of an environment. Interaction also increases awareness, allows for new channels of communication, and supports the conditions that foster a sense of community. Without such interaction, community could not exist [8]. In much the same way, facilitated communication within computer-mediated learning environments can also enhance social interaction and become a source of common identity.

Research studies involving interactivity in online classes reveal that students value opportunities to communicate with their peers and instructors [3]. As Palloff and Pratt relate "what the virtual student wants and needs is very clear: communication and feedback, interactivity and a sense of 
community, and adequate direction and empowerment to carry out the tasks required for the course" [4]. Wiesenberg and Hutton conclude that building social interaction is of critical importance to the creation of a successful computer-mediated learning environment [7].

Online courses that provide a variety of interactive activities, such as polling, debates, reflection, and critique, are able to develop and sustain strong online communities with rich social interaction. However, these interactions do not occur without some challenges.

\section{Challenges to Participation in Computer-Mediated Discussions}

Soliciting students' input on unfamiliar topics or controversial issues in open forums does not appeal to all students. VanDeGrift, Wolfman, Yasuhara, and Anderson identified three primary factors that inhibited students' participation in computer-mediated discussions [5]:

Student Apprehension. Research on communication apprehension shows that some students feel intimidated by discussion questions that require them to voice their personal views regarding sensitive issues [2]. Students will not participate if they perceive their views as stupid or unimportant. Such feelings of apprehension are very common among college students, particularly in larger classes.

Comment Verbalization. A factor closely related to student apprehension is students' ability to put into words their feelings or opinions regarding complex issues. The act of posting comments in a class discussion forum involves a certain amount of personal risk. Students who send messages wonder how others will receive their written thoughts. Individuals who possess fewer cognitive and computer skills can feel even more anxious in their first online class. Online instructors often observe that students have trouble communicating the source of their confusion for fear of sounding incompetent.

Feedback Lag. Timing is another critical factor affecting student participation. A fastpaced asynchronous discussion can discourage student participation by not leaving enough time for students to process presented material. Students who are unsure of the value of their contributions delay posting their comments until the topic is finished. Then, after the class has moved to a new topic, these students believe the "window of opportunity" to contribute to the dialog has passed and leave their thoughts unvoiced.

These challenges to participation represent some of the obstacles to interaction in computermediated discussions. The use of polls addresses these challenges by allowing students to submit their points of view anonymously and obtain immediate feedback that confirms that their views have been recorded and that their contributions can be considered by the group. Consider the advantages of online-polls:

Non-written communication. Online polls provide an alternative to the written word, circumventing problems associated with student apprehension and the inability to verbalize comments. Students cast a "vote" by selecting from a series of pre-defined choices. The polling program collects the individual student responses silently and unobtrusively for the instructor and tabulates the results. The digital feedback is easily 
separated from any identifying information making the communication completely anonymous.

Anonymity. Anonymity also addresses the challenge of student apprehension. In one study involving student participation through computer-mediated systems, the use of anonymous polls increased student participation from fifty percent to nearly eighty percent [1]. In addition, the researchers also found that when students' identities were kept secret, they volunteered more profound and honest comments and observations.

Shared context for feedback. Once student responses have been entered, the polling software generates graphs that illustrate how students voted on a particular item. These graphs can be used as a shared context for feedback illustrating where consensus, or lack thereof, exists. The immediate results circumvent the issue of feedback lag. The instructor also benefits from the shared context since it provides a snapshot of students' perceptions at a given moment in time. Follow-up polls can be administered to track how students' perceptions change over time.

Rapid synthesis of feedback. To parlay student feedback into true class interaction, the instructor can synthesize and respond to the feedback in a timely manner. Depending upon the results of the survey, the feedback may be in the form of more probing questions intended to get students to think critically about the subject matter, or, in the form of a redirection, clarification or explanation of the concept as needed.

Frequent feedback (to instructor and student alike) through polls during a semester is desirable. Through the poll results, students find out where they stand among their peers. They feel more involved and appreciate that their opinions count [1]. Instructors receive valuable input regarding student understanding of the subject matter and may provide a rationale for making adjustments in course content or delivery.

\section{Examples of Poll Use in Online Discussions}

Polling tools can be used to structure and drive, as well as summarize or enhance a discussion. They can also be used for consensus building by enabling students to discuss a topic until they reach a mutual agreement. Polls may also be used to elicit feedback regarding the students' learning experiences. Consider the following examples:

At The University of Texas at Brownsville and Texas Southmost College an instructor for an online graduate course in Educational Technology uses polls to present controversial issues involving the integration of technology into teaching. Through an online poll the instructor submits a controversial statement such as, "Allowing students in grades K-3 to use calculators while working on Math problems would ruin Math education," and requires the class to come to a decision using a jury system on whether this statement is true or false. Students are encouraged to submit their viewpoints asynchronously through a threaded discussion. Those who elected to share their opinions would also be compelled to support them and to consider opposing views. After all the 
arguments are presented, students are asked to vote again. The polling software documents changes in opinion from the time the issue was first presented.

At the University of Minnesota, a nursing professor integrated online polls in a computermediated problem-based learning course to encourage consensus building. The instructor posted typical scenarios for nurses doing intake assessment, such as "a person has come in with an earache." Students were then asked to provide possible causes of the problem and discussed the merits of each suggestion using synchronous chat. The instructor used the polling tool throughout the discussion to enable the class to either accept or reject each suggested cause, generating a short list of likely causes. When surveyed about their use of the web polls, students overwhelmingly responded that they learned more about the material and felt more connected to their classmates and the instructor as a direct result of their interactions [6].

Many instructors use online polls to elicit student feedback regarding class lectures, quality of instruction, or instructor proficiency. Since these polls are anonymous, students are free to make comments without fear of being identified. Angelo and Cross [1] document the positive effects of classroom assessments through anonymous polls. They noted that students appreciated that their comments counted and instructors did not have to rely on guessing to obtain information regarding student satisfaction with the learning experience. In a study conducted to examine the effect of student interaction through a computer-mediated feedback system, VanDeGrift reported that when students provided feedback during a synchronous discussion, most instructors responded by immediately changing the presentation style and by providing more examples and explanations when necessary [5].

\section{Students' Perceptions of Online Polls}

With regard to the use of polls in online courses, an informal poll was taken from graduate students enrolled in the Online M.Ed. in Educational Technology at The University of Texas at Brownsville and Texas Southmost College during the Spring 2005 semester. Students were asked if the use of online-polls enhanced the social interaction in their computer-mediated distance education courses. Sixty-four students chose to respond to the survey from 4 online graduate courses. Figure 1 presents the poll results. 


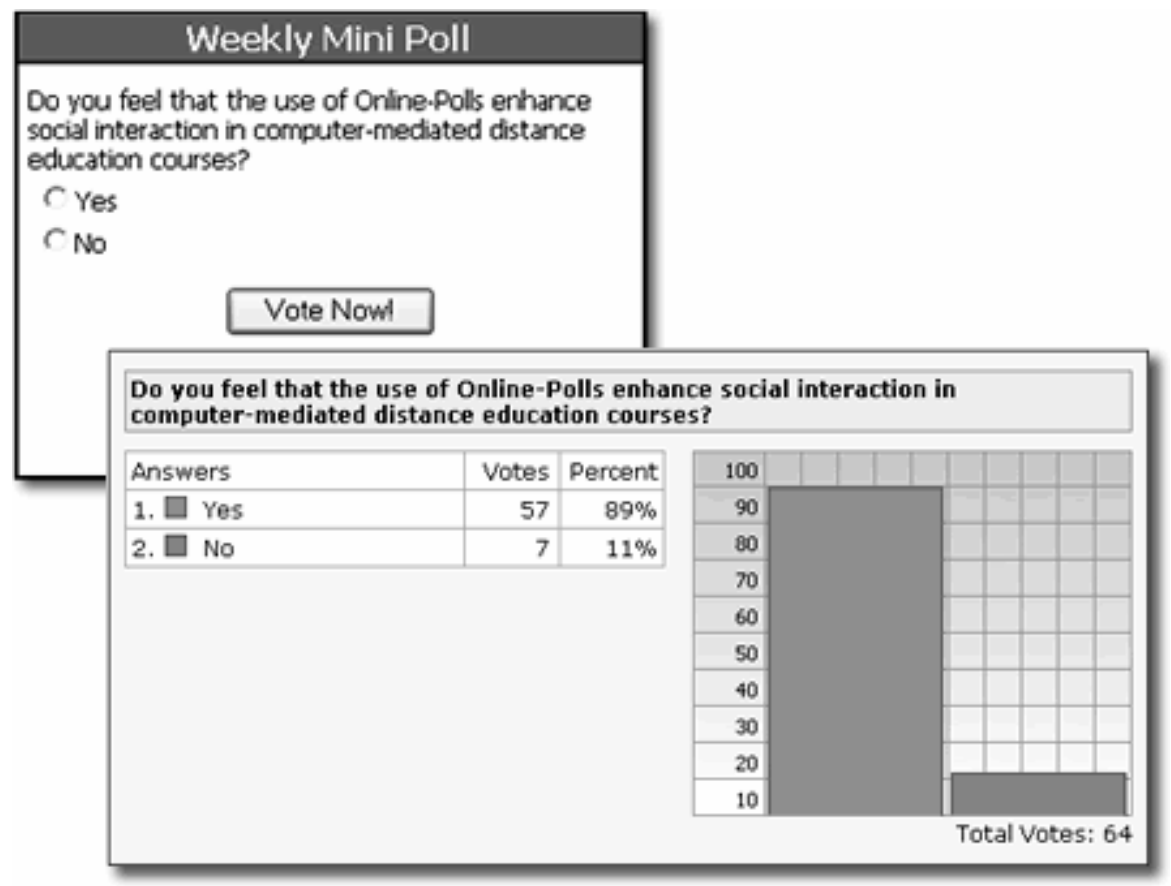

Figure 1. Screenshot of the online poll question and results.

Of the sixty-four respondents, $89 \%(\mathrm{~N}=57)$ indicated that online polls did enhance the social interaction in their online courses while $11 \%(\mathrm{~N}=7)$ indicated that online polls did not enhance the social interaction in their online courses.

In addition to casting a vote, students were also asked to submit their viewpoints regarding the use of online polls in computer-mediated asynchronous discussions. The following is a sampling of responses submitted to the class discussion boards:

"Online polls are one tool that can be used to create the sense of online community. It allows us to see what our fellow classmates think about a specific issue in an easy, nonthreatening way. Newcomers can get a sense of what some of the issues are in the field and get to know students that may be in other classes as well."

"Online polls are a great way to enhance social interaction in a computer-mediated environment. I feel that these "ice -breakers" give us an opportunity to interact with our peers and colleagues. They also contribute increased understanding of issues and provide reinforcement for us."

"As far as the polls go...I have enjoyed the feedback snapshot that the polls offer. I think they are another-and appropriate-tool that an instructor can use to initiate discussion."

"Great tool!! It promotes communication and student interaction. I have taken many online classes, and this is the first class where I have used online polls. These polls are helpful making me feel connected to my peers, and serves as an avenue to 'hear' others' points of view." 
"In my mind, they're used to solicit responses that you may not otherwise receive from your audience... I see them being used as a strategy to get my audience to contribute. This becomes the best reason I've encountered for their utility."

"I like the idea of online polls for enhancing social interaction in synchronous virtual classrooms to wake the crowd up a bit. We actually had fun with an online poll a couple days ago. They do work well. As another student mentioned, the questions and the results may be skewed but they are designed more for the social effect than for the gathering of factual information."

As the poll results also illustrate, not all students had a favorable view of polls. While their point of view was in the minority, their comments brought in to question the validity and reliability of polls:

"As the recent presidential election demonstrated, polls are unreliable. The answers reflect not just people's views, but the mood they were in when they voted. The results can be skewed too easily by the way questions are asked, and by the questions themselves."

"At best, I see polls as conversation pieces, so their social usefulness has value. However, I view every poll with a great deal of skepticism, mostly because they seem to ask white bread questions about white bread issues, and usually to a captive audience."

\section{SUMMARY AND CONCLUSIONS}

A major challenge for today's online instructors involves creating a consistent level of interaction that fosters academic learning and cultivates a community atmosphere. This will require developing strategies that provide students the opportunity to interact with one another in a safe and non-threatening environment. Research on distance education best practices upholds the importance of training new instructors with the skills and knowledge needed to foster dynamic interaction in their online classes [3].

Web-based polls are one tool instructors can use to gauge student opinion regarding key issues, determine class-wide comprehension of important concepts, assess the instructional experience, build consensus, and structure, summarize, or enhance social interaction in computer-mediated asynchronous discussions.

Instructors that want to perform rapid assessments of student opinions will also find online polling tools helpful. By automating the processing of responses, online polls make it easy for instructors to receive instant results. These results can provide valuable information regarding students' perceptions regarding course materials or the delivery of those materials. Online polls are not perfect since students are free to choose whether or not to participate, so the responses are only as good as the coverage. However, most students appreciate an instructor's effort to gather information about their learning experience. The bottom line is that online polls provide a simple, no-cost enrichment of the student's learning experience. 


\section{REFERENCES}

1. Angelo, T. A., \& Cross, K. P. (1993). Classroom Assessment Techniques, (2nd Ed.). San Francisco: Jossey-Bass Publishers.

2. Bowers, J. W. (1986). Classroom communication apprehension: A survey. Communication Education, 35. 372-378.

3. Muirhead, B. (2004, March). Research insights into interactivity. International Journal of Instructional Technology and Distance Learning, I(3).

4. Palloff, R. M, \& Pratt, K. (2003). Virtual student: A profile and guide to working with online learners. San Francisco, CA: Jossey-Bass.

5. VanDeGrift, T., Wolfman, S. A., Yasuhara, K., \& Anderson, R. J. (2002). Promoting interaction in large classes with a computer-mediated feedback system. Technical report, University of Washington, Computer Science \& Engineering.

6. University of Minnesota Digital Media Center. (2004). Using technology to support consensus building. Retrieved January 27, 2005, from http://dmc.umn.edu/spotlight/consensus.shtml

7. Wiesenberg, F., \& Hutton, S. (1995). Teaching a graduate program using computer mediated conferencing software. Paper presented at the Annual Meeting of the American Association for Adult and Continuing Education, Kansas City, MO, November 1995.

8. Wilkinson, K. (1991). The Community in Rural America. New York, NY: Greenwood Press. 